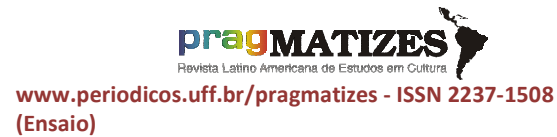
(Ensaio)

\title{
Currículo Lattes: um estudo sobre algumas representações sociais
}

DOI: https://doi.org/10.22409/pragmatizes.v12i22.51049

Ricardo Cortez Lopes ${ }^{1}$

Resumo: o Currículo Lattes é um documento gerado com a inserção de dados de pesquisadores na plataforma de mesmo nome. Ela se torna muito evidente em momentos de controvérsia pública, especialmente quando se descobre alguma fraude vêm a público. Assim, é possível investigar representações sociais sobre este objeto. No presente estudo nos focamos em uma representação, detalhando seu núcleo central (plataforma lattes, instituições e pesquisadores) e seus elementos periféricos (que são desdobramentos do núcleo central). Buscamo-la em comentários postados nas reportagens relativas a fraudes no lattes.

Palavras-chave: Currículo Lattes; plataforma lattes; pesquisadores; instituições; representações sociais.

\section{Currículo Lattes: un estudio sobre algunas representaciones sociales}

Resumen: El Currículo Lattes es un documento generado mediante la inserción de datos de investigadores en la plataforma del mismo nombre. Se hace muy evidente en tiempos de controversia pública, especialmente cuando uno descubre que sale a la luz algún fraude. Por lo tanto, es posible investigar las representaciones sociales sobre este objeto. En el presente estudio nos centramos en una representación, detallando su núcleo central (plataforma lattes, instituciones e investigadores) y sus elementos periféricos (que se despliegan desde el núcleo central). La buscamos en los comentarios publicados en los informes relacionados con el fraude de lattes.

Palabras clave: Currículo Lattes; plataforma lattes; investigadores; instituciones; representaciones sociales.

\section{Lattes Curriculum: a study on some social representations}

Abstract: The Lattes Curriculum is a document generated by inserting data from researchers on the platform of the same name. It becomes very evident in times of public controversy, especially when it is discovered that some fraud is made public. Thus, it is possible to investigate social representations about this object. In the present study we focus on a representation, detailing its central nucleus (lattes platform, institutions and researchers) and its peripheral elements (which are unfoldings of the central nucleus). We look for it in comments posted in reports regarding fraud in lattes.

Keywords: Lattes curriculum; Lattes platform; researchers; institutions; social representations.

\footnotetext{
${ }^{1}$ Ricardo Cortez Lopes. Doutor em Sociologia pela UFRGS/Universidade Federal do Rio Grande do Sul, Brasil. E-mail: rshicardo@hotmail.com - https://orcid.org/0000-0003-0808-7203
} 


\section{Currículo Lattes: um estudo sobre algumas representações sociais}

\section{Introdução}

O interior de cada especialidade guarda elementos simbólicos complexos que exigem um mergulho do analista nas ideias desse grupo para a sua compreensão aprofundada. No caso da atividade acadêmica brasileira, não é muito difícil de se imaginar que um Currículo Lattes possa não ser conhecido por integrantes de fora do campo da pesquisa, ainda mais em um país onde há baixas taxas de matrículas no ensino superior. Por ser assim, em teoria, ele não é de interesse de quem é de fora, pois a informação ali não atrai ninguém.

Porém, como é um documento originando em uma plataforma governamental, ela acaba adquirindo chancela governamental, o que foge de um documento individual e ganha ares públicos. Neste caso, fraudar o lattes é crime. No entanto, como ele não é um resumo, ou seja, não condensa informação, então ele não é significante para quem está fora da dinâmica.

Mas há momentos de controvérsia em que o Currículo Lattes deixa de ser um conhecimento restrito do grupo e alcança outros sujeitos, que podem ter maior ou menor conhecimento sobre esse objeto. Mesmo sem nunca manusear, alguém pode construir uma imagem dele compondo-a com outros saberes prévios. O objeto desse estudo é uma dessas representações possíveis sobre o Currículo Lattes: vamos estudar como comentários realizados por não-usuários da plataforma em páginas da internet expressam significações sobre essa base de dados

Este estudo é de caráter qualitativo, e o corpus analisado são comentários na internet em reportagens em que foram relatadas mentiras em formações disponibilizadas no Currículo Lattes. São nesses momentos em que a formação acadêmica ganha maior relevância, o Currículo Lattes, enquanto registro dessas informações, acaba sendo também problematizado e definido. A investigação se baseou na teoria das representações sociais, buscando a representação social desse currículo para grupos não- 


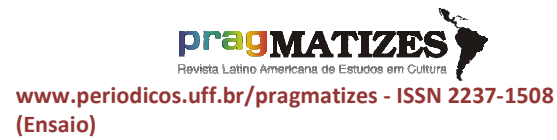
(Ensaio) acadêmicos. A representação foi montada com base em três categorias internas, descobertas a posteriori: 1) Confiança, 2) Instituições e 3) Pesquisadores e por seus respectivos elementos periféricos. Do núcleo central se originaram elementos periféricos, os quais vamos explorar na seção teórico-metodológica. Preliminarmente, podemos esclarecer que o material investigado foi obtido por meio da busca de casos em que algum componente curricular foi adicionado ou omitido por algum pesquisador e que isso foi repercurtido em portais de notícias. Aquelas que possuíam espaço para o comentário de leitores foram a superfície de análise, pois é neste espaço que é possível verificar manifestações de indivíduos que não escreveram o texto. São nestes fragmentos que vai ser possível encontrar representações sociais sobre o Currículo Lattes expressas nas palavras e nos modos como elas são organizadas.

A aproximação com os comentários foi realizada por meio de uma análise de conteúdo, mais especificamente pela técnica da análise categorial, que permitiu extrair a mensagem dos comentários dos comentários e daí sistematizá-la:

[...] após a seleção do material e a leitura flutuante, a exploração foi realizada através da codificação. A codificação se deu em função da repetição das palavras, que uma vez triangulada com os resultados observados, foram constituindose em unidades de registro, para então efetuar-se a categorização progressiva (SILVA; FOSSÁ, 2015, p. 8).

Assim, do site, os comentários foram compilados para uma folha em separado. Nesse espaço é que foi aplicada a grelha categorial, que são o conjunto de categorias que servem para extrair sentido do corpus analisado e que nos permitiram acessar a estrutura simbólica da representação. Essas categorias foram formuladas a priori com base no referencial da teoria das representações sociais - detalharemos essas relações na próxima seção. Após essa apresentação, vamos realizar uma revisão bibliográfica sobre o Currículo Lattes para, posteriormente, analisar os dados e encontrar o núcleo central e os elementos periféricos da representação social. 


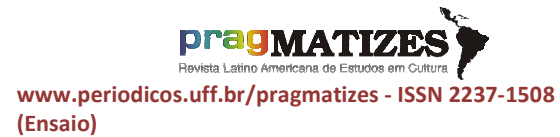
(Ensaio)
Referencial teórico: teoria das representações sociais e o

\section{Currículo Lattes}

A teoria das representações sociais, por conta de sua abordagem e epistemologia, permite a investigação da variedade de pensamentos que circulam dentro de determinada formação social. A representação social é uma tentativa de duplicata discursiva de um referente/, de algum objeto, e que é compartilhada socialmente por algum grupo e que descreve e normatiza determinado objeto (LOPES, 2019). A representação tenta transformar 0 desconhecido em familiar por meio dos processos de ancoragem e objetivação (MOSCOVICI, 2011), no momento em que alguma coisa percebida é lida pelos saberes prévios e concebida como real, e assim se constrói. Mas o que seriam as representações sociais?

[...] são entidades quase tangíveis. Circulam, se cruzam e se cristalizam sem cessar em nosso universo cotidiano através de uma palavra, um gesto, um encontro. A maior parte das relações sociais estreitas, dos objetos produzidos ou consumidos, das comunicações trocadas estão impregnadas delas. Sabemos que correspondem, por uma parte, à substância simbólica que entra em sua elaboração e, por outra, a prática que produz dita substância (MOSCOVICI, 2011, p. 27)

Nesse caso, há representações formuladas sobre muitos objetos, como por exemplo representações sobre grupos sociais. Quando se estudam representações, na medida em que indivíduos compartilham representações eles formam um grupo social. Consoante a essa delimitação, o nosso intento é de estudar a representação social sobre o referente currículo lattes. Esse objeto é significado para muitos grupos. Para o grupo dos pesquisadores, cujo uso desse currículo é direto, há um tipo de representação; para outros grupos sociais que não o usam, há outras significações possíveis. Não estamos, no entanto, afirmando que há uma dicotomia: afinal, não são em absoluto todos os pesquisadores que utilizam lattes e nem todos que utilizam lattes são pesquisadores: há diferentes gradações entre usuários e nãousuários. Ou seja, apenas nisso há um fator de diferenciação da representação a nível de variedade, e outro nível de variação é a histórica. Compreender essa variação permite que haja mais clareza e distinção entre 


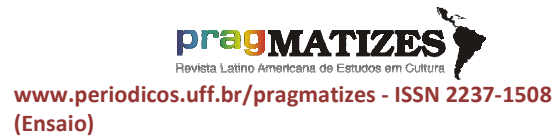

as diferentes representações, por conta do maior levantamento de elementos distintivos (LOPES, 2019). Essa variedade da representação social é acompanhada por uma variabilidade interna, que são o núcleo central e os elementos periféricos. O que seriam eles?

Haveria assim, em primeiro lugar, um sistema central. constituído pelo núcleo central da representação, ao qual são atribuídas as seguintes características: 1. é marcado pela memória coletiva, refletindo as condições sóciohistórica; e os valores do grupo; 2 . constitui a base: comum, consensual. coletivamente partilhada das representações, definindo a homogeneidade do grupo social; 3. é estável, coerente. resistente ã mudança, assegurando assim a continuidade e a permanência da representação; 4. é relativamente pouco sensível ao contexto social e material imediato no qual a representação se manifesta. Suas funções são gerar o significado básico da representação e determinar a organização global de todos os elementos (SÁ, 1996, p. 22)

Ou seja, o núcleo central é descritivo, guarda a memória e é permanente no interior da representação. Os elementos periféricos, por seu turno:
Em segundo lugar. haveria um sistema periférico, constituído pelos demais elementos da representação. que. provendo a "interface entre a realidade concreta e o sistema central" [...] atualiza e contextualiza as determinações normativas e consensuais deste último. daí resultando a mobilidade, a flexibilidade e a expressão individualizada das representações sociais. $\mathrm{O}$ sistema periférico apresenta, portanto. as seguintes características: 1. permite a integração das experiências e histórias individuais; 2 . suporta a heterogeneidade do grupo e as contradições: 3 . é evolutivo c sensível ao contexto imediato. Sintetizando. suas funções consistem, em termos atuais e cotidianos, na adaptação à realidade concreta na diferenciação do conteúdo da representação e, em termos históricos, na proteção do sistema central (SÁ, 1996, p. 22)

Ou seja, os elementos periféricos são, basicamente, compostos de julgamentos individuais sobre os elementos do núcleo central, o que mantém a sua definição. Assim, ele encarna o potencial de mudança da representação social, o que mantém o núcleo estabilizado. A coleta de dados buscou seguir essa leitura teórica, como mostra a figura 1 : 
Figura 1 - esquema teórico-metodológico

\begin{tabular}{|l|l|l|}
\hline & Plataforma Lattes: quem emite o curriculo & $\left\{\begin{array}{l}\text { Fidedignidade } \\
\text { Utilidade }\end{array}\right.$ \\
Currículo Lattes & Instituições: quem aceita o currículo & $\left\{\begin{array}{l}\text { Políticas } \\
\text { Universidade }\end{array}\right.$ \\
& Pesquisadores: quem redige o currículo & $\left\{\begin{array}{l}\text { Úteis } \\
\text { Inúteis }\end{array}\right.$ \\
\hline Representação & Núcleo Central & Elementos Periféricos \\
\hline
\end{tabular}

Fonte: autoria própria

Nesse esquema é possível perceber que a representação vai ser investigada por meio de 3 categorias, que compõem parte do núcleo central da representação - Plataforma Lattes, Instituições e Pesquisadores, pois a presença desses três símbolos é essencial na tentativa de descrever, e sem formulá-las previamente não existe uma representação. No entanto, das descrições resultam julgamentos nem sempre unívocos, o que resultam em subcategorias, que resultarão em variedades dessa mesma representação. $\mathrm{Na}$ seção seguinte vamos revisar bibliograficamente esse núcleo central, pois serão estudados todos os seus integrantes e suas interações factuais.

\section{Revisão bibliográfica dos elementos do núcleo central}

Por mais que a prática de distribuição de currículo nas relações de trabalho tenha se dado após a urbanização e a expansão da rede de ensino, o currículo é uma palavra de origem muito antiga. Ela provém do latim, e descrevia o caminho de um cidadão pelos cargos. (SACRISTÁN, 2013, p. 16). Ocorre, portanto, um filtro de seus êxitos e ocultamento dos percalços. Ou seja, o currículo é uma descrição da atuação positiva na área e substitui a palavra do próprio candidato a um emprego (ALMEIDA, 2017). No mundo do trabalho, atualmente, o currículo precisa ser resumido, ele não pode ser a 


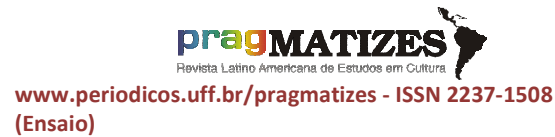
(Ensaio) descrição completa da trajetória profissional, por conta do volume de candidatos.

Para um candidato em início de carreira, uma página é suficiente para o CV. No caso de profissionais mais experientes, o limite pode ser de duas a três páginas, na opinião de Paulo Dias, da Mariaca. "Currículos muito longos e prolixos dificultam a localização de informações importantes", explica

O currículo, mais do que uma trajetória individual, é um resumo tendencioso, e precisa se adaptar para a vaga e também à alta demanda de currículos recebidos por recrutadores (GASPARINI, 2014). Ou seja, um currículo é uma construção dinâmica, o que o torna um objeto valioso para as Ciências Sociais.

Se o currículo vitae é produzido individualmente pelos candidatos a uma vaga, de modo que cada um se responsabiliza pela produção do documento particular, ele não possui fé pública, muito embora sanções sejam possíveis caso seja descoberta a fraude. Por seu turno, o Currículo Lattes é um documento público, cuja responsabilidade também é dos preenchedores e cuja adulteração pode ter consequências jurídicas.
Quando um currículo é preenchido, os dados são direcionados para uma base de dados chamada de Plataforma Lattes. A sua elaboração seguiu a tendência das Tecnologias da Informação:

(a) a consolidação das pesquisas em redes sociais que permitem as conclusões do quadro 2; (b) os avanços nas TICs que permitiram maior produtividade no desenvolvimento de sistemas de conhecimento; (c) a disponibilidade de uma ampla variedade de portais de informação resultantes das novas tecnologias e plataformas de governo eletrônico. Nesse cenário, as novas plataformas de governo eletrônico, [...] podem dispor de uma gama de sistemas de conhecimento especialmente projetados para análise e indução de redes de pesquisa. Um dos exemplos recentes é o conjunto de sistemas de conhecimento da Plataforma Lattes, uma arquitetura de informações em CT\&I desenvolvida para o CNPq gerir suas atividades de fomento e para integrar em um mesmo ambiente os diversos atores ligados ao sistema nacional de inovação do país. Além de viabilizar a interoperabilidade dos sistemas de informação das agências federais, a Plataforma Lattes tem racionalizado 0 processo de gestão de CT\&I. A estrutura arquitetônica da Plataforma Lattes é composta de níveis conceituais (camadas) levados à prática por meio de instrumentos e métodos que compreendem desde 0 arquivo de dados sistematizados nas unidades de análise até a extração de conhecimento 
referente à informação nacional sobre CT\&I (BALANCIERI, 2005, p. 68)

A Plataforma Lattes, portanto, gera os currículos, porém não é sua única finalidade, pois a ideia mais ampla foi inserir qualquer tipo de informação relacionada com as atividades de Ciência, Tecnologia e Inovação do país no Ministério da Ciência e Tecnologia, o que alimenta políticas públicas por meio de "currículo, de grupos e de instituições de pesquisas" (NOBRE; FREITAS, 2017, p. 31). Por ser um banco de dados, é possível utilizar as informações para diversos cruzamentos que visam

[...] a integração dos sistemas de informação das principais agências de fomento do País, foi desenvolvida a Plataforma Lattes, sendo resultado do esforço do Ministério da Ciência e Tecnologia (MCT), CNPq, FINEP e CAPES/MEC [...] Hoje, fazem parte da Plataforma Lattes 0 Diretório dos Grupos de Pesquisa, Sistema de Currículos Lattes, Diretório de Instituições, Buscas, Sistema Gerencial de Fomento e Formulário os Latted de Propostas (AMORIN, 2002, p. 18)

No início, a plataforma sistematizou informações que já estavam disponíveis na época, porém em locais diferentes e muitas vezes sem estarem digitalizados: "A Plataforma Lattes contempla atualmente conjunto de bases de dados, sistemas de informação, diretórios de serviços e portais Web, compartilhados por gestores, técnicos de governo, comunidade científica e sociedade [...]" (PACHECO, 2003, p. 20). Ou seja, são dados públicos e que podem ser acessados por qualquer um que tenha acesso a uma rede de internet.

Ou seja, a plataforma ajudou a transformar a atividade de pesquisa no país em uma série de variáveis mensuráveis. Em um primeiro momento, tratava-se de um software a ser instalado na máquina, de modo que o aplicativo enviava as informações para a base de dados posteriormente: "Após o download da versão 1.5 , o currículo pode ser, a qualquer momento, criado ou atualizado por pesquisadores, profissionais e estudantes interessados" (AMORIN, 2003, p. 18); adiante começou a ser possível editar diretamente no site da plataforma, como ocorre até hoje. Uma vez inseridos os dados pelos usuários, 


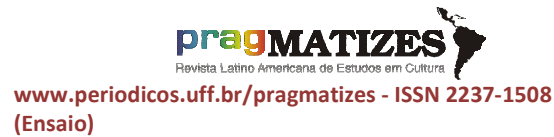
(Ensaio) eles podem ser coletados de muitas maneiras:

O Lattes Extrator é uma ferramenta desenvolvida pelo próprio $\mathrm{CNPq}$ em que apenas instituições previamente cadastradas podem extrair da Plataforma Lattes informações relativas ao seu Corpo docente, Corpo Discente e demais colaboradores, caracterizando-se, portanto, como uma ferramenta de uso restrito. O Lattes Miner constitui-se em uma ferramenta automatizada, de domínio público, que pode ser utilizada para extração de informações da Plataforma Lattes com relação a alguns indicadores de desempenho dos docentes, pesquisadores, alunos e Programas de Pós-Graduação (ALVES; YANASSE; SOMA, 2012). Já o Scriptlattes, além de ser uma ferramenta também de domínio público e que possibilita a extração da produção acadêmica de um determinado grupo de pesquisadores, também é capaz de gerar relatórios e gráficos, disponibilizando-os em páginas na web (FERRAZ; QUONIAM; MACCARI, 2014, p. 6)

Portanto, o levantamento e a análise dos dados da plataforma são feitos com o envolvimento de muitos indivíduos, que trabalham em muitos aspectos. Esse tipo de sistematização é importante pois, "[...] nos últimos anos, a ciência brasileira vem apresentando um rápido crescimento de produção acadêmica, impulsionada pelas políticas de ciência e tecnologia" (MENA-CHALCO; DIGIAMPIETRI; CESAR-JR, 2013, p. 2). Ou seja, a plataforma conseguiu organizar a sua estrutura antes da explosão de inserções nos anos 2000, na massificação do sistema de ensino superior. Houve uma inspiração bem clara para o nome da plataforma, que:

[...] recebeu o nome de Lattes em homenagem ao grande cientista brasileiro Cesare M. Giulio Lattes. Este professor e pesquisador é curitibano e conhecido mundialmente como um dos responsáveis pela descoberta do méson pi, a partícula subatômica que garante a coesão do núcleo do átomo (AMORIN, 2003, p. 18)

O nome, portanto, remete a uma conquista da ciência brasileira por meio de um cientista. Nesse caso, a sedução está na associação com um pesquisador de renome a nível internacional no ramo da física, que foi a ciência preponderante por um bom tempo. Nesse caso, esse pesquisador condensa uma série de significações para passar para a plataforma.

Um traço importante da Plataforma Lattes é que ela não é automatizada, e sim manual na inserção de dados, sem uma integração com múltiplas bases de 


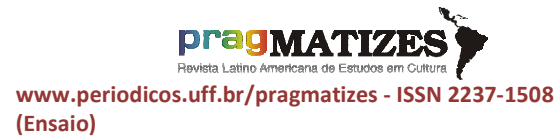
(Ensaio) dados. Quando se trata de dados de instituição, ela é que tem o dever de atualizá-los, o que confere certa segurança porque os funcionários públicos responsáveis podem ser punidos disciplinarmente se incorrerem em fraudes (BRASIL, 1990). No entanto, há usuários individuais, que é o caso do currículo de tipo lattes, com o "[...] objetivo de criar um instrumento curricular único" (AMORIN, 2002, p. 18). Mas qual seria a definição mais precisa do currículo?

Criado em 1999 pelo CNPq, o
Currículo Lattes é um
componente da Plataforma Lattes
e tornou-se o padrão nacional de
registro das atividades
acadêmicas e profissionais
realizadas pelos estudantes e
pesquisadores do país.
Atualmente, o currículo lattes é
adotado pela maioria das
instituições de fomento,
universidades e institutos de
pesquisa para avaliação de
pesquisadores, professores e
alunos. Ter este currículo
atualizado na plataforma é um
dos critérios para a obtenção de
bolsas e auxílios pelos
estudantes de pós-graduação
(NOBRE; FREITAS, 2017, p.31)

Ou seja, o Currículo Lattes é o intermediário entre os projetos de pesquisa e as verbas necessárias para sua consecução. Nesse sentido, mesmo não haja o preenchimento por um servidor, há esse mecanismo e a lei para garantir o máximo de transparência nas informações: "Art. 297 - Falsificar, no todo ou em parte, documento público, ou alterar documento público verdadeiro: Pena reclusão, de dois a seis anos, e multa" (BRASIL, 1940, s/p). Ou seja, há uma tentativa de coesão por meio desses dois mecanismos. Em termos de programação,

Os dados do currículo estão estruturados de maneira hierárquica. O sistema está dividido em seis módulos, sendo dois para preenchimento de dados (módulo Dados Gerais e módulo Produção) e quatro referentes a ferramentas disponíveis para gerenciar as informações cadastradas. Os módulos Dados Gerais e Produção são utilizados para o preenchimento de dados do interessado [...] O módulo Dados Gerais está dividido em dados pessoais (identificação e endereço), dados profissionais (formação acadêmica/titulação, atuação profissional, prêmios e títulos honoríficos, linhas de pesquisa) e outras informações relevantes. Já no módulo Produção, o usuário cadastra ou atualiza sua produção bibliográfica, técnica e artística/cultural, bem como suas orientações concluídas. Os outros módulos (arquivo, ferramentas, acessórios e ajuda) participam do gerenciamento da utilização do sistema (AMORIN, 2002, p. 18) 
Assim, cada usuário lança as informações e a plataforma as aceita, não havendo uma conferência posterior. Assim, há uma importância maior, de modo que "[...] motiva os pesquisadores a manter seus currículos com informações corretas e atualizadas, tornando a Plataforma Lattes uma fonte adequada para análise da produção científica brasileira" (FARIAS; VARGAS; BORGES, 2012, p. 1). No entanto, o currículo em específico prescinde da necessidade de confiança para a adequação enquanto fonte de dados, o que pode nem sempre acontecer se levarmos como verdadeira a seguinte literatura jornalística:

- Dilma Rousseff: segundo reportagens, em seu Currículo Lattes constavam informações sobre uma graduação em ciências sociais, além de Mestrado e Doutorado em Economia, mesmo sem as defesas de monografias. Sobre essas inserções, a expresidente afirmou não conhecer sua a procedência (MENDONÇA, 2009);
- Damares Alves: a atual ministra Mulher, da Família e dos Direitos Humanos afirmou, em uma ocasião, que possuía dois mestrados, um em Educação e outro em Direito. Posteriormente ela afirmou que se tratava de uma escolaridade obtida dentro do meio religioso (DA REDAÇÃO, 2019);

- Ricardo Salles: há relatos de que $\mathrm{o}$ atual ministro do Meio Ambiente se anunciava como "Mestre em direito público" por Yale, porém não teve seu diploma confirmado pela instituição (BERMÚDEZ, 2020);

- Sérgio Moro: o ex-ministro da Justiça e Segurança Pública foi acusado de ter feito plágio em um artigo publicado em periódico. A sua co-autora assumiu o plágio (SOBRINHO, 2020);

- Carlos Decotelli: o ex-ministro da educação teve levantadas suspeitas de plágio na sua dissertação de mestrado, declarou ser doutor sem uma defesa de monografia de tese e um pós-doutorado na Argentina, 
todas as informações não confirmadas (G1, 2020a);

- Wilson Witzel, o governador do Rio de Janeiro, que atualmente é doutorando em Ciência Política pela Universidade Federal Fluminense, afirmou que tinha um estágio sanduíche em Harvard, porém não foi comprovado que ele participou da seleção para a bolsa (G1Rio, 2019);

- Joana D'arc Félix afirmou que possuía um pós-doutorado pela Universidade de Harvard, porém uma reportagem solicitou a documentação comprobatória e esta não existia (CHAPOLA, 2019);

- Ricardo Vélez Rodríguez teve apontado 22 erros em seu Currículo Lattes, que foram analisados como uma inflagem artificial das suas produções acadêmicas (BÉRMUDEZ, 2020);

- Abraham Weintraub, ex-ministro do Ministério da Educação e Cultura, foi apresentado pela equipe governamental como tendo um doutorado, porém no Lattes do ministro aparecia um
Mestrado e um MBA (CHAPOLA, 2019);

- Bel Pesce, famosa empreendedora, afirmou que possuía diplomas no Massachusetts Institute of Technology (MIT), o que foi investigado por um youtuber na época, que chegou a montar um dossier (CHAPOLA, 2019);

- Alexandre Morais, ex-ministro da Justiça, possuía uma inserção de pós-doutorado simultâneo ao seu doutoramento. Essa informação foi posteriormente apagada, além de ter sofrido uma acusação de plágio por um autor espanhol (REDAÇÃO, 2017).

Como se vê, há uma grande gama de finalidades na questão curricular. Em todos esses casos, o título não era pré-requisito para a atividade - pois isso, de fato, é bem regulamentado e depende da apresentação do título para comprovação. Assim, não detectamos um caso em que foi apresentado um diploma de fato falsificado. O que ocorreu foram omissões ou 
acréscimos de informações não comprovadas na plataforma ou no currículo vitae. Portanto, é possível obter status com o título, porém não é possível burlar pré-requisitos.

Sem dúvida o caso que teve maior repercussão foi o do professor Decotelli, pois foi possível encontrar nas suas matérias comentários que afirmavam que suas atitudes foram uma reação às relatadas situações de racismo. Ou seja, há outras questões levantadas além daquelas relacionadas aos próprios dados, que mobilizaram defesas mais apaixonadas.

\section{Análise dos comentários}

As declarações foram copiadas para um arquivo separado, como corpus textual. Em seguida, foi aplicada a grelha categorial, que selecionou os trechos que eram significantes para responder ao problema de pesquisa, pois permitem a aproximação com as representações sociais expressas em palavras. A metodologia de exposição será apresentado os resultados encontrados nas três categorias, que compõem o núcleo central.

\section{Plataforma}

Nesta categoria foram alocadas as falas que remetem ao nível de confiança que se pode ter nos dados da plataforma. Em um primeiro nível, seria a plataforma refletora das reais qualificações dos profissionais? Em um segundo nível, seria a plataforma útil para uma finalidade maior do que refletir os dados nela inseridas? Esses elementos periféricos engendram percepções do mundo vivido e são o alvo dessa sessão.

\section{Fidedignidade}

A questão da fidedignidade da plataforma, aqui definida como a comprovação do que aparece nela com documentos externos a ela, aparece de algumas maneiras. A primeira é com relação à falta de verificabilidade das informações digitadas pelo usuário: "Quando ainda não era ministro suas mentiras davam certo, ninguém investigou se as informações no currículum eram verdadeiras. Porém como ministro, virou vitrine, e quando foram investigar..........."(G1, 2020b, s/p). Nesse lado emerge a questão da verificabilidade: ela não acontece pela iniciativa dos próprios responsáveis 
pela plataforma. Houve também quem reforçou a questão de que essa característica espaço para aproveitadores: "Esse cara foi indicado, certamente em parte por seu currículo... Mentiu descaradamente, usou isso para obter vantagem (professor ganha extra quando tem maior titulação)..." (G1, 2020c, s/p). Nesse caso, como já afirmamos anteriormente, não é possível o trabalho do professor, especificamente, sem o título - porém, aparece a ideia que a mentira no currículo é beneficente e torna a plataforma não confiável.

Outra fala se refere ao prestígio obtido por meio da "mentira" junto à plataforma: "É uma pena, se lembrarmos da longa lista de nomes que já tiveram alegações erradas em seus currículos, e isso vai desde ao Alexandre de Moraes a ex-presidente Dilma, parece que tentar obter status assim é mais comum do que parecia" (G1, 2020c, s/p). Ou seja, segundo esse relato, um título acadêmico, de fato, possui relevância nas relações sociais, pois permite, no mínimo, acesso a cargos. $O$ interessante é que essa percepção fica mais forte em outro trecho: "Brasil é campeão mundial de corrupção. A falsificação de diplomas é um grande business aqui e muita gente importante 'comprou' vários níveis de graduação acadêmica" (G1, 2020c, s/p). Assim, a sociedade brasileira construiu um ambiente no qual mentir a qualificação pode trazer benefícios, algo que a plataforma favorece ao não verificar.

Houve depoimentos que foram mais a fundo na sua relação: "Primeira grande contribuição do Decotelli: desmascarar a credibilidade Plataforma Lattes. Nunca acredite nessas ferramentas digitais. Nada substitui 10 perguntas olho no olho por quem quer preencher uma vaga" (G1, 2020c, s/p). Ou seja, a plataforma impessoaliza uma relação que deveria ser pessoal, pois essa validação é a mais relevante na comparação com os recursos que a plataforma pode oferecer - e foi o que permitiu que o potencial ministro fosse indicado ao cargo. Para a plataforma ser crível seria preciso o seguinte esforço: "Plataforma Lattes é só para honestos, militares não deveriam poder participar" (G1, 2020a, s/p). Nesse comentário fica evidente que é preciso certo voluntarismo por parte do usuário para que haja a correção dos dados, o 


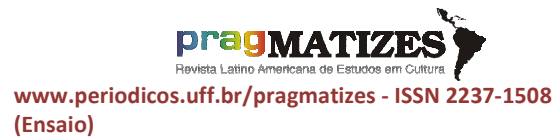
(Ensaio)

que reforça que a impessoalidade prejudica a veracidade. Mas houve quem ainda depositasse esperança na impessoalidade: "Deixa o cara em paz! Ele não vai ser ministro mesmo! Quem tem que supervisionar a veracidade é a plataforma Lattes. Esta sim deve tomar providências, não só para este caso, mas para todos os outros" (BRASIL, 2020, s/p). Ou seja, aqui a pessoalidade é que conduz à fraude, e não o contrário. Ainda, apareceu certo conhecimento sobre a questão legal:

Alguém disse que publicar informações falsas no Lattes é conduta tipificada como crime no Código Penal. Se não me falha a memória, foi o que a Dilma teria feito. Por que não foi considerado crime? O UOL bem que poderia fazer um paralelo entre os dois casos [Dilma e Decotteli]. Por que não o faz? (BERMÚDEZ, 2020, $\mathrm{s} / \mathrm{p})$

Nesse caso, houve o erro também de quem acredita que a Plataforma Lattes pode funcionar sem a verificação externa, com base na coerção da lei (o usuário, claramente, não conhecia a coerção por meio dos financiamentos). Assim, os escândalos adquirem certa função didática:

O ex-presidente Lula, cujo endereço deveria ser a [Complexo Penitenciário da] Papuda, junto com a maior parte da cúpula dos partidos pelos crimes já conhecidos (por isso sou favorável a candidaturas independentes), não pode ser acusado de mentir no currículo (como a Dilma, por exemplo). Infelizmente, durante oito anos, o ex-presidente beneficiado pelo STF para ficar em liberdade apesar de seus crimes, a todo momento ressaltava e ressalta que não estudou, não lia livros ou jornais. Um desserviço à nação, assim como é a fraude Decotelli, que já tirou o respeito da plataforma Lattes. É O assassinato da educação no Brasil (G1, 2020c, s/p)

Ou seja, a educação como um todo já é desacreditada enquanto instituição, pois a instrução formal não resulta necessariamente em contribuições concretas e diretas para a sociedade que a financia por meio de impostos. Essa descrença, por outro lado, pode ser sanada se forem seguidas sugestões dos internautas:

Eu particularmente acho que a plataforma Lattes deveria notificar, solicitasse confirmação das instituições de ensino superior toda vez que alguém inserisse alguma titulação, ou no limite, revisasse todas as pós graduações, a partir do mestrado, de todos os "pesquisadores" cadastrados na plataforma. Seria como uma "reforma agrária" intelectual, teria tanto grileiro de diploma que ficaríamos abismados (G1, 2020a, s/p).

A fala também aponta para certa representação sobre 0 
funcionário público, em especial o gestor, atribuindo-Ihe certa imperícia: teriam mesmo os gestores não cogitado esse modus operandi? Aparentemente a resposta é não para esse comentário, de modo que este propõe uma atitude que consiga romper com o simulacro por meio da verificação de dados, e que isso acabaria com as mentiras. Trata-se, evidentemente, de um simulacro possível pela falta de credibilidade da plataforma:

Disimular es fingir no tener lo que se tiene. Simular es fingir tener lo que no se tiene. Lo uno remite a una presencia, lo otro a una ausencia. Pero la cuestión es más complicada, puesto que simular no es fingir [...] Así, pues, fingir, o disimular, dejan intacto el principio de realidad: hay una diferencia clara, sólo que enmascarada. Por su parte la simulación vuelve a cuestionar la diferencia de lo "verdadero» y de lo «falso», de lo «real» y de lo «imaginario». (BAUDRILLARD, 1993, p. 55)

Ou seja, a plataforma permite a construção de uma imagem de pesquisador, sendo que este pesquisador de fato existe e não é aquele que frauda, porém o simulacro permite que isso seja superado na performance. No entanto, a ausência do papel comprobatório anula esse simulacro em pouquíssimos segundos. É claro que anular uma grande quantidade de simulacros exigiria toda uma equipe para o viabilizar, o que talvez não seja aplicável para o serviço público como está configurado atualmente. Esse mesmo feeling parece ser compartilhado em um outro comentário:

[...] claro que com esta forma de validação proposta por você, a falta de verdade, mentiras em currículos lattes vão ser difíceis de se sustentar ... ainda mais partindo de alguém que deveria ser exemplo para a nação ... ou seja, ser Ministro da Educação ... complemento que esta seriedade deveria ser para todos! (G1, 2020a, s/p)

Ou seja, esse comentário expressa que, mesmo se houvesse controle, haveria burlas do sistema, o que novamente coloca a discussão dos limites da pessoalidade e da impessoalidade. Porém, há a esperança de que isso seja contornável: "Na verdade, entendo que estas instituições poderiam criar mecanismos de validação das informações registradas, até mesmo para garantir que fato como esse não venham a acontecer" (G1, 2020a, s/p). Portanto, circula certa esperança na reformulação da política da plataforma. 
Um último comentário desse tópico é aquele relacionado a quando o simulacro dá errado: "Se eu fosse ele, JAMAIS atualizaria meus dados nesse site. Isso é para pessoas que trabalham na área acadêmica. Para se Ministro não precisa ter Currículo na plataforma Lattes, óbvio" (BRASIL, 2020, s/p).

Com relação a essa subcategoria, a conclusão mais geral é de que a Plataforma (impessoal), em si, não é, atualmente, fiel com os dados, 0 que permite que pesquisadores (pessoas) criem um simulacro com chancela governamental. Até este momento, assumiu-se que, atualmente, a plataforma cria a dissonância. Mas, em uma condição ideal na qual todos os dados fossem reais, ela seria útil? A resposta será dada na próxima seção.

\section{Utilidade}

A representação sustenta que há a possibilidade de fraudes na plataforma por conta de sua inserção individual. No entanto, se é excluída a possibilidade do simulacro, a plataforma pode ser útil para outros fins? Nesta subcategoria vamos encontrar quem afirme que sim e quem afirme que não.

Com relação a quem considera a Plataforma inútil, vamos analisar o primeiro comentário: "Até a Dilma, presidenta da República, mentiu no Lattes! Plataforma que só serve pra encher linguiça e o saco dos alunos" (G1, 2020b, s/p). Ou seja, a possibilidade de mentir acaba com qualquer princípio de utilidade da plataforma para qualquer fim, uma vez que suas informações não são verdadeiras. Esse comentário, aparentemente, sabe da questão da coerção por meio do financiamento, e por isso afirma que ele é utilizado para aborrecer os seus usuários, criando mais simulacros. Mas há outras utilidades:

Decotelli e a imprensa conseguiram detonar a plataforma Lattes e o Linkedln. Que credibilidade têm essas bases de Curricula Vitae!? Para vocês verem que a Plataforma Lattes e Linkedln e afins são pura enganação. Ele veio para isso, mostrar a safadeza que deve campear nessas plataformas de auto-promoção. Profissional que é bom, faz. Não escreve! Papel (e agora, plataformas digitais) aceita tudo. Agora tem que ter batalhões de checadores de Curricula. Imaginem quantos picaretas não estão por aí dando aulas como doutores kkkkkkkk(G1, 2020c, $\mathrm{s} / \mathrm{p}$ ) 


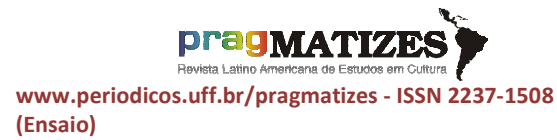
(Ensaio)
Aqui também entrou a rede social Linkedln, que também é uma plataforma de cadastramento de currículo, porém voltado apenas para a questão profissional. Assim, o currículo é um papel, que permite que seja feita uma fraude sem a descoberta servindo o currículo como um palco que separa o ator de seu público. No entanto, há uma ideia de que muitas pessoas conseguem fazer valer 0 simulacro, o que o torna real. Todavia, é uma mentira fácil de desmascarar:

Gente, veja as coisas pelo lado bom: o Decotelli, a Globo e os investigadores de hora vaga (na pandemia é o que mais sobra) prestam um serviço público ao desacreditar a Plataforma Lattes, Linkedln e afins. Qual a credibilidade que existe no que se escreve por lá. Imaginem a quantidade de picaretas dando aulas por aí que turbinaram o seu Lattes. É claro que daqui pra frente as escolas superiores vão ter que fazer um pente fino por aí. (G1, 2020a, s/p)

Ou seja, a plataforma é inútil no sentido de que consegue manter esse jogo de aparências, o que fica bem evidente quando há escândalos com a plataforma, algo a ser resolvido por uma investigação simples - e que evidentemente não será conduzida.
Por fim, houve também falas mais taxativas: "Que zona é Plataforma Lattes!" (G1, 2020a, s/p). Isso demonstra que há uma percepção de falta de regulamentação, o que induz a falta de utilidade. $E$ isso fica evidente quando se fala da própria maneira que o pesquisador brasileiro constrói seu currículo "[...] bem recheado na forma, mas vazio de conteúdo... deixem o cara pra lá, coitado! Vaidoso..." (BRASIL, 2020, s/p). Nesse ponto, o quantitativo substitui o qualitativo $e$ mesmo quem não mente, na verdade, seria apenas incompetente.

Sobre a utilidade, encontramos apenas um comentário: "Depende da consciência e caráter de um amigo, se o cara é 171 e quer enganar todo mundo o problema é dele e não dá plataforma, o Wikipédia também é assim, o problema não está na plataforma mas sim no caráter de cada um!" (G1, 2020c, s/p). Acionar a Wikipedia, um site internacional, leva a discussão para outro nível, colocando o problema ético apenas no nível do ator, individualizando-o. Dessa maneira, a plataforma pode ser útil desde que haja veracidade na ação do usuário. 
A conclusão mais geral sobre esse elemento periférico é que a utilidade da plataforma não está no seu uso, mas sim em sua capacidade de desvelar o simulacro, pois a realidade é facilmente evocável para destruir a mentira e assim evidenciar até mesmo as farsas do próprio poder estatal. Se a discussão assume essa dimensão, é possível também se problematizar as próprias instituições.

\section{Instituições}

Como vimos, os dados inseridos na plataforma são alvo de dúvida constante. Essa atribuição de significados se amplia para as instituições que se relacionam com a plataforma. As instituições políticas, por exemplo, a usam como referência; já as universidades cedem os certificados. Qual a dinâmica das duas na construção dos elementos periféricos da representação?

\section{Políticas}

Atualmente, segundo o estatuto do servidor (BRASIL, 1990), os políticos geralmente ocupam cargos eletivos ou de livre nomeação e, nesse caso, nem sempre o diploma em si tem a influência decisiva para a posse e a entrada em exercício. No entanto, o currículo, como reflexo da trajetória prévia, pode favorecer a indicação para um cargo, por parte de um tomador de decisão.

Nesse caso, há quem afirme que as instituições políticas são "ingênuas" com relação à produção dos currículos:

O que me espanta é como o
governo nomeia pessoas sem
checar a veracidade das
informações contidas no
curriculum. O que não falta ao
Estado é mecanismo de controle
e fiscalização. Esse tipo de erro é
primitivo. Depois acham ruim
quando as pessoas falam que
tem muito marajá no serviço
público que não faz
absolutamente nada. E fico
imaginando o tanto de pessoas
com diploma falso que facilmente
adentra em cargos relevantes
(G1, 2020c, s/p).

Ou seja, o interesse político é mais um véu ao já presente véu do simulacro curricular, o que é inesperado por conta dos mecanismos de controle. Nesse momento, as instituições estão sendo contestadas na sua capacidade de investigação de informações mesmo que acionadas para tal fim, como mostra a seguinte fala:

Não tenho autoridade para tal, mas na minha humilde opinião, todos deveriam comprovar suas 


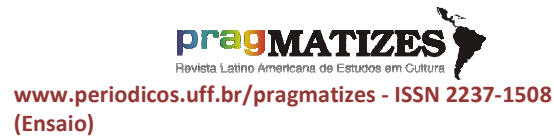

documentações para estes cargos de tanta relevância, nós que somos mais simples quando vamos preencher uma vaga de emprego pedem documentação até da cueca que você usa, minha opinião (REDAÇÃO, 2017, $\mathrm{s} / \mathrm{p})$

Nesse caso, é mostrada uma noção de cisão entre o cidadão e o político, que não precisa de comprovações externas ao seu próprio discurso para ser aceito no seu espaço de atuação. Houve também quem visualizou relações entre a dimensão política e a dimensão educativa:

Esse sr. e seus impropérios
assemelham-se ao estelionato.
Parece que suas bases
educacionais estão alicerçadas
na falsificação, enganação,
mentira. Por tudo já lido, é mal
exemplo para o sistema
educacional, educadores,
educandos, famílias. O MPF deve
investigar se com essas
falsificações, não foi beneficiado
com gratificações, bolsas de
estudos, se não assumiu cargo
de professor com o currículo falso
tirando o direito de outro
concorrente. Ele não tem obras
acadêmicas ou literárias para
chamar de suas. Demissão
urgente, educação é coisa séria!
(G1, 2020a, s/p)

É claro que não é possível atuar na educação sem as comprovações de títulos, o que mostra que há certo privilégio na dimensão política ao render um foco na relação pessoal.
Nesse caso, as relações de poder anulam o peso da educação formal do currículo, colocam a trajetória abaixo da influência pessoal.

O elemento periférico coloca as instituições políticas lidando com 0 Currículo Lattes de maneira bastante displicente, pois o objetivo é manter a política acima de qualquer outra relação. Seria de se esperar que essa desconfiança permanecesse no âmbito da política, que utilizam os frutos da atividade universitária, porém ela transborda para as próprias instituições educativas, como as de ensino superior.

\section{Universidades}

Basicamente, nesta seção ocorre um processo associativo. A universidade é fundida com instituições políticas, de modo que os membros são equivalentes do ponto de vista moral, muito embora sua ação ocorra por meio de diferentes documentos. Assim, haveria uma equivalência moral entre os políticos e os educadores.

Seguindo essa lógica, tal como ocorre com os políticos, nas universidades seria fácil descobrir as irregularidades apenas procedendo-se 


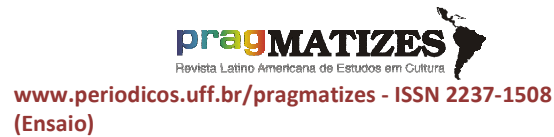
(Ensaio) averiguações simples: "Se fizerem uma investigação nas universidades públicas com fizeram com esse ministro, vão constatar que a maioria dos mestrados e doutorados são plágios, feitos única e exclusivamente para engordar salários. Se eu fosse esse ministro, faria um pente fino" (G1, 2020a, s/p). Ou seja, um critério rígido conseguiria acabar facilmente com 0 simulacro no interior das universidades, pois os diplomas serviriam para gerar progressões na carreira dos servidores.

No caso do ministro Decotelli, por exemplo:

Será uma vergonha se a FGV não tomar uma atitude séria, a altura do seu nome, e o Portal LATTES também deveria tomar uma posição a respeito, pois o Portal foi utilizado para propagar essas mentiras, colocando todos os que usam essa plataforma sob um olhar de desconfiança (SCHELP, 2020, s/p)

O internauta está rogando por uma purificação dessa dimensão também, e a Fundação Getúlio Vargas é só um exemplo, que poderia tomar uma "atitude séria" com relação ao caso. A "atitude séria" seria, justamente, a dissolução dos laços pessoais e o apelo para o mérito da pesquisa, pois apenas ela conseguiria trazer de volta a confiança na instituição e na própria plataforma. Assim, a Instituição de Ensino Superior deve mostrar que não coaduna com o pesquisador e mostrar que se trata de uma mácula.

Outro comentário é o de que:

Reflete a realidade da área acadêmica do Brasil, repleta de doutores com teses e cursos inúteis, e pessoas que tentam esses títulos de qualquer forma .

Principalmente no serviço público estes títulos servem para alçar promoções de cargo, sem medir a competência e produtividade da pessoa.

As regras favorecem estes episódios (G1, 2020b, s/p)

Se fizesse uma varredura encontrariam muitos servidores com doutorado, mestrado, e cursos afins utilizados para progressão funcional e aumento salarial só de papel.

A FGV também deve explicações, como permite que alunos com plágio sejam aprovados? agora perceberam? e quantos outros estão na mesma situação? Isto é a famosa venda de diplomas.... mas como é da famosa não fala, culpam só o aluno, fosse uma pequena a instituição também estaria sendo criticada (G1, 2020b, s/p)

As universidades públicas podem até não lidar diretamente com dinheiro público, porém seus professores estão diretamente relacionados com remuneração 
quando se trata de títulos. Outro comentário vai num sentido parecido: "Vão dizer também que o Ministro da Educação é capacitado e que tal tipo de mentira (que pode levar a obtenção de dinheiro ilícito, já que os títulos aumentam o salário dos professores) não tem problema algum" (G1, 2020c, $\mathrm{s} / \mathrm{p})$. Fica evidente que há, no mínimo, discordâncias de grupos sociais com relação ao modo como os servidores avançam na sua carreira, também, por meio de qualificação profissional por meio de títulos acadêmicos.

Nesse caso, as universidades emitiriam títulos sem o correspondente mérito acadêmico, voltado exclusivamente para a produção de progressão funcional. É o caso do recurso aos plágios: "Se eu fosse este ministro, faria um pente fino em todos os mestrados e doutorados dos professores das universidades públicas, com certeza a grande maioria seriam plágios, feitos única e exclusivamente para engordar salários" (G1, 2020c, s/p). O plágio está economizando tempo do pesquisador e produzindo um documento útil para a progressão funcional, mesmo que não contribua para a ciência num geral. Mas há comentários que afirmam que isso não é um fato escondido, mas que é um segredo público: "90\% dos artigos acadêmicos no Brasil são plágios. TODO mundo sabe disso, inclusive a galera do judiciário....." (G1, 2020a, $s / p)$. Nesse momento, há uma generalização de que a universidade não cumpre com a sua função de gerar conhecimento viável e útil para o restante da sociedade.

Em resumo, nesta categoria a universidade aparece como, no mínimo, omissa ou, de maneira mais agravante, como parte do esquema de corrupção. Diferentemente das instituições políticas, nas universidades não há corrupção do ponto de vista jurídico, mas há ao menos do ponto de vista ético, talvez até mesmo epistemológico. É nesta última dimensão que entra a discussão sobre os pesquisadores, usuários dos currículos e que lançam as informações.

\section{Pesquisadores}

Dado que a plataforma aceita as inserções e quem se responsabiliza por elas são os usuários individuais, é relevante também estudar a imagem resultante deles para os grupos 


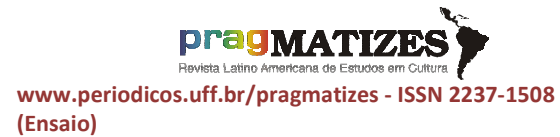
(Ensaio) sociais. Daí emergem apreciações morais positivas (a utilidade dos próprios pesquisadores) ou negativas (inutilidade dos pesquisadores em si), associando-os ao contexto circundante ou não. Vamos começar pelo primeiro caso.

\section{Úteis}

Mesmo que se admita que o Currículo Lattes possa ser mentiroso e impreciso, ainda é possível se considerar que os usuários (ou parte deles) são socialmente relevantes - no caso de pesquisadores, epistemologicamente relevantes. Podemos observar, nesse elemento periférico, comentários que não desacreditam o pesquisador:

Esse desgoverno fabrica
vergonha atrás de vergonha para
tirar a atenção dos escândalos
tenebrosos que aparecerem
diariamente. O povo se desdobra
para estudar e fazer pesquisa
com dificuldades absurdas,
redibra esforços para lançar as
informações no currículo Lattes e
de repente vê gente lançando
informações infundadas. Triste. E
pelo que lembro não e o primeiro
caso de ministros do desgoverno.
Mais uma vergonha. Mas foco
nos escândalos graves e
criminosos e no saque ao estado
brasileiro patrocinado por
empresários medíocres e e
Inescrupulosos e banqueiros
trilionários. E foco também nas

ações entreguistas das riquezas nacionais aos interesses yankes, de quem os últimos apoiadores veneram a bandeira (SCHELP, 2020, s/p).

Ou seja, quem se "desdobra para estudar e fazer pesquisa" acaba sendo preterido por indivíduos que optam por mentir nos seus currículos, sem nenhum tipo de investigação por trás disso - o que significa ausência de sanção. Dessa maneira, permanece o infundado uma atitude recompensada financeiramente, sendo o simulacro valorizado em cima da trajetória real.

Outro mecanismo de purificação dos pesquisadores infundados dos relevantes é por meio da assunção da culpa diretamente para indivíduos fraudadores: "Esse sujeito não merece o cargo, pois se um de nós mortais mentíssemos a respeito de nosso CV , em qualquer empresa seríamos renegados e assim seja para esse senhor...."(SCHELP, 2020, s/p). Nesse sentido, aumenta-se a distância entre o político e os cidadãos. Ou seja, é uma desagregação grupal: o pesquisador mentiroso não é o mesmo que o pesquisador no geral.

Outro mecanismo de purificação é o de corrupção posterior do pesquisador. Nesse caso, a carreira 
pode acabar se misturando a política por alguns intermédios e assim o simulacro corrompe a busca pela episteme:

Chegou para o governo como "Doutor" e vai sair como gari. Antes, bom lembrar, que esse cidadão vinha ganhando muito dinheiro com esse currículo, através de palestras, livros e a própria indicação ao FNDE, quando em junho do ano passado na Câmara, foi anunciado de forma pomposa, como "Doutor" alemão e argentino...(G1, 2020c, $\mathrm{s} / \mathrm{p})$

Ou seja, a pesquisa, em si, é importante, mas há essa possibilidade do simulacro se passar por real. Dessa maneira, não é o título e o conhecimento que são o problema de fato, mas sim a fraude. Nesse ponto, há um problema generalizado com a fraude dos méritos:

É bem por aí. Dr. em fraudar currículo é só o que tem no Brasil. Na política, na academia, estão em todo lugar. Gente "posuda" que se auto intitula doutor. Basta olhar para a rapaziada que se forma em direito, a maioria exige que os chamem de Dr. Foi aprovado no ENEM em medicina, pronto, já é Dr. (G1, 2020a, s/p)

Nesse ponto de vista, há o simulacro de alguns alunos que, antes mesmo de obter o título, já exigem o tratamento correlato - o que não significa que haja a contestação do saber em si mesmo. Há a "pose", mas ele é a mentira de uma capacidade real, que é potencial. Assim, é a arrogância em si que é ruim, mas ainda é possível um trabalho mais detido por trás disso.

Assim, o pesquisador que é útil está na negação do fraudulento. Ele está, justamente, no bastidor da pesquisa científica, e não possui a mesma visibilidade pois não aceita participar do simulacro. Ele perde oportunidades de ganho por conta dos fraudadores, o que ainda causa alento quanto ao campo científico. Porém, ainda há falas que descartam tanto a simulação quanto os pesquisadores no geral, o que é o tema da próxima sessão.

Inúteis

A mentira sobre uma informação sem um atestado respectivo pode ser danoso para a figura pública em si. No entanto, há falas que apontam que nem mesmo os títulos legitimamente relatados possuem relevância. Nesse caso, o conteúdo da ciência não está sendo adequadamente preenchido pelos pesquisadores. 


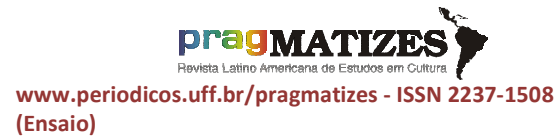

A primeira fala a que vamos fazer referência é a seguinte: "Tudo fake. Temos sempre de desconfiar desses currículos extensos, pomposos, muitos deles só de olhar dá para entender que alguém para tê-los teria de ter sete vidas como um gato. Por trás dos grandes feitos temos as grandes mentiras" (SCHELP, 2020, $\mathrm{s} / \mathrm{p})$. A pompa, no caso, é o simulacro, que se reveste de realidade por meio da extensão do documento, que busca inviabilizar o questionamento - e daí reside a desconfiança. Nesse caso

Se até o do ministro é assim, imagino o quão fake não é o currículo de muitos alunos e alunas por aí. Muitos só entendem de Canabis [maconha] e querem criticar. E se diproma tá nesse pé de fakenews, imaginem publicações... "Aí, ela pubrico na Science..." Tá.... O pior do Brasil, é o brasileiro. O raça!!!(G1, 2020b, s/p)

Ou seja, o ministro, que está no topo da escala, provavelmente chegou a ela por meio das mentiras, tanto em diplomas quanto em publicações. Logo, todos que estão abaixo dele precisam mentir para conseguir galgar espaço, pois sua especialidade está em "Canabis". A estrutura, como um todo, está corrompida pelo simulacro, o que inclui o modo como se faz ciência.

Há ainda outras contestações aos conteúdos investigados pelos pesquisadores, ao menos os brasileiros:

Se o do ministro é assim, me pergunto se muitos acadêmicos songa minhas realmente publicaram tudo que falam. Até currículo no Brasil "é para inglês ver". E pior é a massa que compra diproma em faculidade particular sem boa pontuação. Muitos pseudograduados ainda ganham comissão. O MEC deixando a desejar na validação dos produtos que ele mesmo oferece(G1, 2020b, s/p).

A expressão "para inglês ver" expressa a compra de títulos, que não são acompanhados da trajetória e nem do conhecimento que culminam no papel oficial. A troca financeira, nesse caso, complementaria todo um sistema público fraudulento (o MEC), o que inclui aquilo que é pesquisado. Ou seja, o simulacro é generalizado, já se tornou uma espécie de DNA. Outro comentário se refere à eficácia da formação, o ponto inicial da carreira de um pesquisador:

PELAMORDEDEUS. Concordo que o sujeito tem a obrigação de informar verdades sobre seu currículo, mas já tivemos nessa pasta importantíssima, doutorados, pós doutorados e 


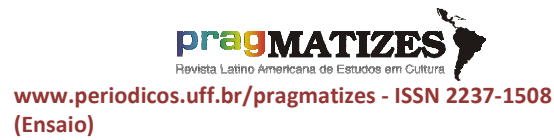

tantos outros cheios de títulos, e alguns que mal dominavam 0 idioma, e muitos no final da história, independente do nível de conhecimento, foram medíocres no resultado. Dá uma chance ao cara. Se der errado, desce o sarrafo (G1, 2020c, s/p).

Ou seja, mesmo com toda a trajetória curricular verdadeira não há garantia de que haverá sucesso epistemológico, o que é irônico porque ocorre justamente no campo da educação, no qual houve uma dedicação prévia. Nesse caso, o comentarista prefere alguém com vivências externas ao ambiente de pesquisa por conta da irrelevância desse saber em seu sentido puro, considerando que a crítica pública pode dar conta de substituir 0 ocupante do cargo que não corresponda.

Encontramos também comentários que remetem a certo ceticismo extremado:

Currículos e títulos acadêmicos não servem para nada - só confirma que as pessoas tem informação o que não é sinônimo de conhecimento. Senão vejamos, a maioria dos professores da universidades públicas tem títulos até para colocar no lixo, no entanto no ranking das 1000 melhores universidades do mundo da Time
High Education ${ }^{2}$ as universidades públicas aparecem na pior colocação a partir do número 800. Nesse caso os título desse idiotizantes travestidos de professores só servem para enfeitar um lugar, a latrina - sem contar com os inúmeros escândalos de corrupção envolvendo a feitura de tais cursos! (BERMÚDEZ, 2020, s/p)

Ou seja, o sistema educacional brasileiro não consegue dar conta de produzir uma educação que possa, no mínimo, equivaler à praticada em outros países. Nesse sentido, as informações não se transformam em conhecimento e não há um saber de fato produzido e que possa ser útil para a sociedade circundante. Assim, os cargos educacionais se mostram ocupados, novamente, pelas relações pessoais e a ciência, em si mesma, se torna um simulacro.

Por fim, há um comentário mais jocoso, que parodia a trajetória de um acadêmico:

Me sinto envergonhado por este senhor idoso, eu que fiz mestrado em vários botecos como degustador de bebidas, fiz doutorado em tomar chopp, depois defendi a tese e fiz pós doutorado em tomador de cerveja, agora vem esta pessoa e

\footnotetext{
${ }^{2}$ https://www.timeshighereducation.com/worlduniversity-rankings/2020/worldranking\#!/page/0/length/25/sort_by/rank/sort_o rder/asc/cols/stats
} 


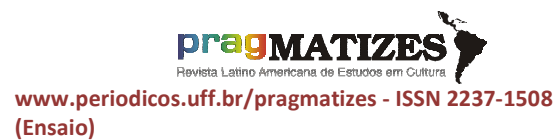
(Ensaio) falsifica todo seu currículo, a $\mathrm{ABI}[\mathrm{N}]$ não serve para nada só para sustentar um general de pijama, se fosse a SNI [Serviço Nacional de Informações, fundada em 1964], eles saberiam até $\mathrm{o}$ corte de cabelo deste indivíduo (G1, 2020a, s/p)

Nesta fala fica evidente que há toda uma estruturação de currículo que é substituída por assuntos não relacionados com pesquisa (cerveja bebidas). A paródia, nesse caso, busca ser engraçada por conta da verossimilhança. É possível perceber o reforço da ideia de que os pesquisadores levam um modo de vida boêmio. O simulacro, no entanto, seria facilmente, segundo este comentário, pelo SNI. Ou seja, o governo, com boa vontade, poderia acabar com essa estrutura que corrompe até mesmo a própria ciência.

Deste tópico, podemos retirar que o pesquisador acaba sendo inútil por conta da corrupção da própria pesquisa. Os pesquisadores não estão voltados para a atividade investigativa, mas sim para objetos boêmios e por vezes políticos. E, mesmo que haja validade na ciência, ela não é mais relevante do que o pensamento pragmático. Como se vê, há muitas significações envolvidas em cada um dos elementos periféricos, que serão analisados conjuntamente na próxima sessão.

\section{Análise global dos dados: a representação social do Currículo}

\section{Lattes}

Nesta seção vamos analisar os aspectos da representação social do Currículo Lattes juntando os dados em uma síntese final. É evidente que existem muitas representações possíveis sobre esse mesmo objeto, porém o que nos interessa é esta cujos elementos investigamos.

No núcleo central, podemos perceber que o Currículo Lattes é expressão de uma plataforma de credibilidade abalada e que serve como referência para instituições corrompidas para uma grande miríade de pesquisadores.

Nos elementos periféricos podemos observar que esses entes percebidos assumem diferentes significações. Esses elementos divergem com relação a uma credibilidade para a ciência e para o pesquisador ou um ceticismo com relação a eles - nesse sentido, a confiança se expressa em uma dimensão macro (a precisão da 
ciência) e numa dimensão micro (a honestidade intelectual

do pesquisador). A representação transcende o campo e se encontra com a política, acionando interpretações e promovendo fusões e recusas. Ou seja, é o saber prévio de outras vivências ressignificando a inserção de dados e a análise deles. Assim, a falta de credibilidade pessoaliza as relações e gera renda por diferentes mecanismos - dessa maneira, os usuários comportam-se na intenção ou na prática como políticos.

Desse conjunto de dados é possível derivar algumas conclusões sobre os assuntos fundidos. Essa representação, antes de tudo, é atravessada por conhecimentos prévios, que funde três entes: a trajetória (o pesquisador), o diploma (a instituição) e o próprio currículo (o documento). Todas elas em relação à representação arrolada.

Com relação ao pesquisador, pode-se observar que há uma particularidade no trabalho científico: o resultado dele são produções. As produções são as "conquistas", e elas são relevantes na medida em que se evidenciam, não em que se resumem, mas naquilo que elas são provas das conquistas. O valor de um pesquisador está no resultado de seu trabalho, que é a pesquisa, e que passa por diferentes matizes - desde qualis de eventos e revistas até localidades, todos esses fatores devem ser levados em conta para aferir o mérito individual de cada conquista e assim produzir a sedução de quem observa o currículo.

Com relação ao diploma. A formação universitária é relevante em si mesma no Brasil, porém a atividade de pesquisa, para alguns brasileiros, parece não ter a mesma apreciação, como se houvesse um detour epistemológico. No entanto, o diploma ainda possui algum tipo de reconhecimento social, especialmente na administração pública, que pode contar para a progressão funcional.

Com relação ao currículo. O Currículo Lattes é cumulativo e não um resumo, como o é o vitae - o que transforma o Currículo Lattes na trajetória per se do pesquisador. Sua credibilidade está na publicação, e por isso é muito mais fácil verificar sua veracidade do que o vitae. Mesmo que fosse possível resolver a questão da credibilidade do currículo lattes com a comprovação da plataforma, ainda assim o problema parece ser com o 
próprio sistema educacional como um todo por parte desta representação social.

\section{Considerações finais}

Este artigo se dedicou a estudar uma representação social dos currículos alocados na Plataforma Lattes para grupos que não se declararam acadêmicos, no seu núcleo central e nos seus elementos periféricos. O princípio do estudo foi uma revisão bibliográfica da historicidade do objeto por meio de um estudo bibliográfico dos elementos do núcleo central, seguido de uma investigação sobre os comentários deixados nas páginas de notícias que anunciavam mentiras sobre 0 preenchimento do Currículo Lattes, as quais expressam os elementos periféricos

O material foi tratado por meio das categorias, que correspondem ao núcleo central: Plataforma desdobrada em imprecisão e inutilidade -, Instituições - políticas e universitárias - e Pesquisadores - úteis e inúteis. Os resultados mais gerais apontam para representações do Currículo Lattes, junto a esses usuários, como um simulacro de títulos e documentos - maneira de garantir renda para funcionários públicos e uma falsa sensação de competência.

Outra questão relativa à plataforma lattes de fato é a necessidade de uma representação social positiva e que seja ampliada para os não-usuários, que é o que se evidenciou nesta pesquisa. A falta de credibilidade da plataforma pode influir na relevância dos próprios pesquisadores num geral, o que pode levar a alguns resultados críticos para a ciência. Um deles é a descrença nas pesquisas desenvolvidas, o que pode resultar em perda de financiamento ou mesmo pode abrir espaço para práticas não-científicas que respondam a problemas científicos (como é o caso das Fake News).

\section{Referências bibliográficas}

ALMEIDA, Carlos M. Costa. O "Curriculum Vitae" em Cirurgia. Revista Portuguesa de Cirurgia, n. 42, p. 51-54, 2017.

AMORIN, Cristiane V.. Organização do currículo: plataforma Lattes. Pesqui. Odontol. Bras., São Paulo, v. 17, supl. 1, p. 18-22, maio 2003.

BALANCIERI, Renato et alli. A análise de redes de colaboração científica sob as novas tecnologias de informação e comunicação: um estudo na 


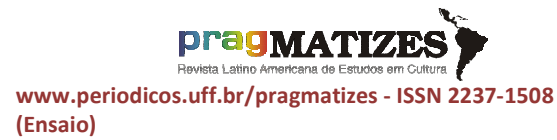

Plataforma Lattes. Ciência da informação, v. 34, n. 1, p. 64-77, 2005.

BAUDRILLARD, Jean. Cultura $y$ simulacro. Divinópolis: Kairós, 1993.

BERMÚDEZ, Ana Caroline. Entenda as acusações contra a vida acadêmica do novo ministro da Educação. UOL. $2020 . \quad$ Disponível em https://educacao.uol.com.br/noticias/20 20/06/27/entenda-as-acusacoescontra-a-vida-academica-do-novoministro-daeducacao.htm?cmpid=copiaecola2020. Acesso em: 16 jul. 2020.

BRASIL. Código Penal. Decreto-lei $n^{\circ}$ 2.848, de 7 de dezembro de 1940 . Código penal, 1940.

BRASIL. Decotelli ainda é ministro no Lattes. $\quad$ O Antagonista. 2020. Disponível em: https://www.oantagonista.com/brasil/de cotelli-ainda-e-ministro-no-lattes/.

Acesso em: 16 jul. 2020.

BRASIL. Estatuto do Servidor. Lei $\mathrm{n}^{\circ}$ 8.112, de 11 de dezembro de 1990. Brasília, DF, 1990.

CHAPOLA, Ricardo. Joana D'Arc e outras personalidades que mentiram no currículo. Veja SP. 2019. Disponível em:

https://vejasp.abril.com.br/cidades/joan a-darc-professora-diploma/2019.

Acesso em 21/07/2020.

DA REDAÇÃO. Damares já se apresentou como mestre em educação e direito sem ter diploma, diz jornal. Isto é. 2019. Disponível em: https://istoe.com.br/damares-ja-seapresentou-como-mestre-emeducacao-e-direito-sem-ter-diplomadiz-jornal/. Acesso em: 21 jul. 2020.

DE FARIAS, Lucas R. et alli. Um sistema para análise de redes de pesquisa baseado na Plataforma
Lattes. Anais da VIII Escola Regional de Banco de Dados, Curitiba, PR, Brasil, 2012.

DIAS, Thiago M. R. et alli. Modelagem e Caracterização de Redes Científicas: Um Estudo Sobre a Plataforma Lattes. BRASNAM - II Brazilian Workshop on Social Network Analysis and Mining, 2013. p.10-20.

DIGIAMPIETRI, Luciano A et alli. Minerando e Caracterizando Dados de Currículos Lattes. In: BRAZILIAN WORKSHOP ON SOCIAL NETWORK ANALYSIS AND MINING (BRASNAM), 1. , 2012, Curitiba. Anais do I Brazilian Workshop on Social Network Analysis and Mining. Porto Alegre: Sociedade Brasileira de Computação, ago. 2012.

FERRAZ, Renato Ribeiro Nogueira; QUONIAM, Luc; MACCARI, Emerson Antonio. Inovação no Planejamento Anual e Trienal do Preenchimento da Plataforma Sucupira: Uso da Ferramenta Computacional Scriptlattes. XVII SEMEAD Seminários em Administração, v. 18, 2014.

G1 Rio. Witzel incluiu em currículo doutorado com intercâmbio em Harvard, mas nunca cursou a universidade. G1. 2019. Disponível em: $\quad$ https://g1.globo.com/rj/rio-dejaneiro/noticia/2019/05/22/witzelincluiu-em-curriculo-doutorado-comintercambio-em-harvard-mas-nuncafrequentou-a-universidade.ghtml. Acesso em: 21 jul. 2020.

G1. Currículo 'não deveria ser objeto de mentiras' e inconsistências de Decotelli são algo 'gravíssimo'; veja repercussão com entidades. G1. 2020a. Disponível em: https://g1.globo.com/educacao/noticia/ 2020/06/30/entidades-se-posicionamsobre-inconsistencias-no-curriculo-decarlos-alberto-decotelli-ministro-da- 


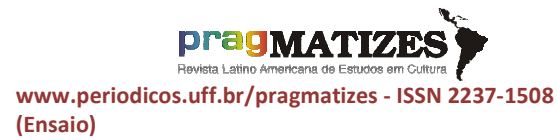

educacao.ghtml. Acesso em: 16 jul. 2020

G1. Entenda as polêmicas sobre os títulos acadêmicos do novo ministro da Educação, Carlos Alberto Decotelli. G1. 2020b. Disponível em: https://g1.globo.com/educacao/noticia/ 2020/06/29/entenda-as-polemicassobre-os-titulos-academicos-do-novoministro-da-educacao-carlos-albertodecotelli.ghtml. Acesso em: 16 jul. 2020.

G1. Professora de universidade na Alemanha nega que Decotelli tenha obtido apoio de empresa para fazer pós-doutorado. G1. 2020c. Disponível em:

https://g1.globo.com/educacao/noticia/ 2020/06/30/professora-deuniversidade-na-alemanha-nega-quedecotelli-tenha-obtido-apoio-deempresa-para-fazer-posdoutorado.ghtml. Acesso em: 16 jul. 2020.

GASPARINI, Claudia. 10 erros que fazem seu currículo ir para o lixo. Exame. 2014. Disponível em: https://exame.com/carreira/10-errosque-fazem-o-seu-curriculo-ir-diretopara-o-

lixo/\#: :text=Para\%20um\%20candidat o\%20em\%20in\%C3\%ADcio,de\%20inf orma\%C3\%A7\%C3\%B5es\%20importa ntes\%E2\%80\%9D\%2C\%20explica.

Acesso em: 20 jul. 2020.

LOPES, Ricardo Cortez. Evasão e persistência de alunos de graduação da Universidade Federal do Rio Grande do Sul: um estudo moral das representações sociais. (Doutorado em Sociologia). Universidade Federal do Rio Grande do Sul, Porto Alegre, 2019.

MENA-CHALCO, Jesús $P$.; DIGIAMPIETRI, Luciano A.; CESAR-
JR, Roberto M. Caracterizando as redes de coautoria de currículos Lattes. In: Anais do I Brazilian Workshop on Social Network Analysis and Mining. SBC, 2012.

MENDONÇA, Alba Valéria. Dilma admite erro em currículo e diz que cumpriu créditos de pós-graduação. G1. 2009. Disponível em: http://g1.globo.com/Noticias/Politica/0,, MUL1221626-5601,00-

DILMA+ADMITE+ERRO+EM+CURRI

$\mathrm{CULO}+\mathrm{E}+\mathrm{DIZ}+\mathrm{QUE}+\mathrm{CUMPRIU}+\mathrm{CRE}$ DITOS+DE+POSGRADUACAO.html.

Acesso em: 21 jul. 2020.

MINING (BRASNAM), 2. , 2013, Maceió. Anais do II Brazilian Workshop on Social Network Analysis and Mining. Porto Alegre: Sociedade Brasileira de Computação, ago. 2013 . p. 116-121.

MOSCOVICI, Serge. Representações sociais: investigações em psicologia social. Petrópolis: Vozes, 2011.

NOBRE, Lorena Neves; FREITAS, Rodrigo Randow de. A evolução da pós-graduação no Brasil: histórico, políticas e avaliação. Brazilian Journal of Production Engineering, v. 3, n. 2, p. 18-30, 2017.

PACHECO, Roberto CS. Uma metodologia de desenvolvimento de plataformas de governo para geração e divulgação de informações e de conhecimento. Artigo apresentado em cumprimento a requisito parcial de concurso para professor no INE/UFSC. Florianópolis, 2003.

REDAÇÃO. Questionado sobre PósDoutorado no currículo, Alexandre de Moraes diz que foi "erro da secretaria". Revista Fórum. 2017. Disponível em: https://revistaforum.com.br/noticias/qu estionado-sobre-pos-doutorado-nocurriculo-alexandre-de-moraes-diz- 
que-foi-erro-da-secretaria/. Acesso em 22/07/2020

SÁ, Celso Pereira de. Representações sociais: teoria e pesquisa do núcleo central. Temas em Psicologia, v. 4, n. 3, p. 19-33, 1996.

SACRISTÁN, José Gimeno. O que significa o currículo. In: SACRISTÁN, José Gimeno. Saberes e incertezas sobre o currículo. Porto Alegre: Penso, 2013.

SCHELP, Decotelli não fez pós-doc na Alemanha, diz universidade. UOL. $2020 . \quad$ Disponível em: https://noticias.uol.com.br/colunas/diog o-schelp/2020/06/29/decotelli-naoobteve-pos-doc-na-alemanha-dizuniversidade.htm?cmpid=copiaecola. Acesso em: 20 jul. 2020.

SILVA, Andressa Hennig; FOSSÁ, Maria Ivete Trevisan. Análise de conteúdo: exemplo de aplicação da técnica para análise de dados qualitativos. Qualitas Revista Eletrônica, v. 16, n. 1, 2015.

SOBRINHO, Wanderley Preite. Moro admite plágio em artigo jurídico, mas culpa coautora do texto. UOL. 2020. Disponível em: https://noticias.uol.com.br/politica/ultim as-noticias/2020/06/27/sergio-moroadmite-plagio-mas-advogado-querretratacao-e-cogitaprocesso.htm?cmpid=copiaecola.

Acesso em: 21 jul. 2020. 